\title{
Optic Nerve Regeneration: Considerations on Treatment of Acute Optic Neuropathy and End-Stage Disease
}

\author{
Louise A. Mesentier-Louro ${ }^{1}$ Y Yaping Joyce Liao ${ }^{1,2,3}$ \\ Published online: 8 March 2019 \\ (C) Springer Science+Business Media, LLC, part of Springer Nature 2019
}

\begin{abstract}
Purpose of Review Acute and chronic optic neuropathies lead to irreversible vision loss, prompting considerations of regenerative therapy. Th e insult commonly occurs primarily in the anterior optic nerve, which leads to degeneration of retinal ganglion cells (RGCs) and their axons and loss of oligodendrocytes. We review important aspects of optic nerve regeneration and animal models of disease.

Recent Findings Preclinical studies in animals showed that approaches that improve RGC survival and axon regeneration include neurotrophic factor delivery, genetic manipulation, visual stimulation, and cell therapies, but impact on glia must be also considered. While intravitreal delivery of molecules has been most commonly used, direct targeting of the optic nerve should be considered.

Summary Treatment can differ if targeting acute or subacute vs. chronic optic neuropathies, depending on whether most RGC axons and somata are still present and salvageable, or if somata and axons are gone and need to be replaced. Combined neuron- and glia-directed treatments may lead to more successful vision restoration.
\end{abstract}

Keywords Optic nerve regeneration · Retinal ganglion cells $\cdot$ Ischemic optic neuropathy $\cdot$ AION $\cdot$ Glaucoma

\section{Introduction}

\section{The Human Optic Nerve and Limited Endogenous Regeneration After Injury}

The optic nerve is the only output of the eye. It is a central nervous system (CNS) white matter tract that sends visual information captured by the eye to the brain for interpretation. The human optic nerve is composed of 1.2 million axons of the retinal ganglion cells (RGCs), whose cell bodies are located in the inner layer of the retina

This article is part of the Topical Collection on Regenerative Medicine in Ophthalmology

Yaping Joyce Liao

yjliao@stanford.edu

1 Department of Ophthalmology, Division of Neuro-Ophthalmology, Stanford University Medical Center, Stanford, CA, USA

2 Department of Neurology, Stanford University School of Medicine, Stanford, CA, USA

3 Byers Eye Institute at Stanford University, 2452 Watson Court, Palo Alto, CA 94303-5353, USA inside the globe [1]. Once the unmyelinated axons of the RGCs exit the globe beyond the lamina cribrosa, they become ensheathed by oligodendrocytes [2].

Injury of the optic nerve or optic neuropathy is one of the most common causes of vision loss [3]. Patients with optic neuropathies experience a disconnection syndrome because once the optic nerve is damaged, the visual information can no longer be sent from the eye to the brain for interpretation. Optic neuropathies can occur suddenly or progressively. Insult to the optic nerve leads to disconnection of the RGCs and its axons to the rest of the brain, which means the visual information captured by the retina is no longer transmitted to the brain. In addition, optic nerve insult leads to progressive retrograde and anterograde degeneration, leading to transsynaptic degeneration and thinning of the entire visual pathway [3-5].

In mammals, there is limited endogenous ability for the CNS to regenerate, while cold-blooded vertebrates can spontaneously regenerate an injured spinal cord [6]. After axonal damage, the distal portion of the nerve undergoes progressive degeneration, a phenomenon named Wallerian degeneration (WD), after August Waller's observations made in 1849. In the peripheral nervous system (PNS) of mammals, where 
severed axons regenerate rapidly, WD takes from 7 to 14 days to be concluded. In the CNS, this process is much slower and takes months to years, leading to a prolonged permanence of myelin debris and associated growth-inhibitory proteins [7].

In 1907, Tello, a student of Santiago Ramon y Cajal, studied CNS and PNS regeneration by transecting the optic nerve of adult rabbits and intercalating a piece of autologous sciatic nerve to the nerve stump. He observed that optic nerve axonal sprouts oriented toward the graft and, in one case, the sprouts crossed the scar and penetrated the graft, extending longer distances within it $[8,9]$. Aguayo and coworkers confirmed these observations in the 1980s, demonstrating that the absence of regeneration in the CNS was not necessarily due to an intrinsic inability of central neurons, but rather to the presence of an inhibitory environment [10].

\section{Most Common Optic Neuropathies}

Glaucoma is the leading cause of irreversible blindness worldwide [11], affecting 111.8 million people by 2040 [12]. Vision loss typically occurs in both eyes and often involves peripheral visual field first (e.g., arcuate visual field defect) but can also involve paracentral areas early. As a progressive disease, treatment of glaucoma is focused on chronic lowering of intraocular pressure using eye drops or surgical procedures. However, in some cases, progression of vision loss can occur over years despite maximal medical and surgical intervention to control intraocular pressure, prompting the need for novel neuroprotective and regenerative therapies [13, 14].

Arguably more devastating than glaucoma, acute optic neuropathies often occur in the setting of ischemia (ischemic optic neuropathies), trauma (traumatic optic neuropathy), elevated intracranial pressure (papilledema), inflammation (optic neuritis and neuromyelitis optical spectrum disorders), tumors, and infections [15]. The most common cause of acute optic neuropathy in those younger than 50 years of age is optic neuritis and in those older than 50 years old, anterior ischemic optic neuropathy (AION) [16-18]. Optic neuritis typically presents in the second and third decades and is associated with sudden central vision loss in one eye, pain with eye movement, and overall good visual prognosis despite thinning of the optic nerve. Treatment involves high-dose intravenous corticosteroids in order to improve vision and reduce risk of developing multiple sclerosis. Nonarteritic AION presents as sudden altitudinal (inferior or superior) visual field loss that may or may not involve central vision in one eye. The vision loss is typically severe and irreversible, and sequential involvement of the second eye occurs in about $25 \%$ of patients (10.5-73\%) within 5 years [18]. Like AION, traumatic optic neuropathy typically occurs suddenly without pain in one eye and is typically severe and irreversible. There is currently no effective treatment for AION or traumatic optic neuropathy. In addition to these common optic neuropathies, the optic nerve can also be damaged by compression, inflammation, neoplasia $[19,20]$, hereditary disorders related to mitochondrial dysfunction such as Leber's hereditary optic neuropathy [21, 22], and various neurological disorders including stroke and multiple sclerosis [23, 24]. Treatment for these issues is typically focused on addressing the underlying etiology but no matter what the cause, once atrophy of the optic nerve occurs in all of these conditions, there is currently no treatment that can reverse this atrophy and the corresponding vision loss.

\section{Axonopathy Precedes RGC Death in Optic Neuropathies}

In optic neuropathies, the initial injury occurs in the axons of RGCs, and axonopathy precedes death of the soma [25]. In glaucoma, elevated IOP leads to impaired axonal transport, including transport of brain-derived neurotrophic factor (BDNF) [26], which then lead to somatic degeneration [14, 27]. In AION animal model, massive axonal degeneration occurs within 7 days after onset [28•], which precedes the first peak of RGC death at day 10 [29].

After axonal injury, retrogradely transported signals from the lesion site and lack of trophic support from glia and central targets likely lead to cell death [30, 31]. Other mechanisms of RGC death after axonal damage include excitotoxicity mediated by glutamate receptors and oxidative stress [32]. Retrograde degeneration of axons leads to apoptosis of RGC soma, culminating in irreversible visual loss [20]. The exact mechanism leading to RGC death is still a matter of intense investigation, and several molecular pathways likely converge to result in the loss of RGCs, mainly by apoptosis [14].

\section{Importance of Optic Nerve Glia}

Classically, vision loss associated to optic neuropathies is solely attributed to damage to the neuron due to axonal injury and loss of RGC soma. Because of the focus on neurons, much of the effect of these diseases on glia, including oligodendrocytes, astrocytes, and microglia, is unknown. Glial cells provide support to neurons and axons that is essential for their survival. The visual system is particularly amenable to studies of CNS axons and glia because of the unique anatomy of the optic nerve. The optic nerve contains a tightly packed bundle of optic nerve axons surrounded by differentially distributed populations of glia in the unmyelinated and myelinated portions.

In the unmyelinated optic nerve, astrocytes provide cellular and metabolic support to RGC axons and form the interface between connective tissue surfaces and blood vessels. In optic neuropathies such as glaucoma, there is disrupted intercellular communication between the astrocyte network and gap junctions, reactive astrocytosis, and disruption of metabolic support to axons [33]. Reactive astrocytes encapsulate the lesion 
core forming the "glial scar," which constitutes a barrier to axon regeneration [34]. Astrocytes can acquire protective or deleterious phenotypes [35•], and a better understanding of how these cells behave in different optic neuropathies will help unravel new disease mechanisms and therapeutic targets.

In the myelinated optic nerve, both oligodendrocytes and astrocytes support the RGC axons. While myelination is critical for rapid, saltatory condition of visual information, this means $99 \%$ of the axons' surface area is covered in myelin and there is limited access to glucose and nutrients in the extracellular space. RGC axons are heavily dependent on oligodendrocytes for metabolic support [36]. To meet the high-energy demands of RGC axons, myelin sheath formed by oligodendrocytes is directly coupled to the axons to allow direct transport of energy source for oxidative phosphorylation from glia to axons [37-39].

While axons depend on oligodendrocytes for support, oligodendrocytes also depend on interactions with axon to survive. When axon-glial interactions are lost following axonal damage, oligodendrocytes fail to breakdown myelin and become quiescent or die by necrosis, apoptosis, or autophagy [7, 40]. Indeed, inefficient myelin clearance is seen as one of the reasons why CNS axons do not regenerate. In contrast, PNS Schwann cells and blood-borne macrophages collaborate to clear myelin and allow neuronal regeneration [41]. Therefore, more studies regarding the impact of axonal injury on oligodendrocyte function and survival are needed to promote CNS axonal regeneration and functional recovery.

\section{Animal Models of RGC Axonal Injury}

There are many animal models of optic neuropathies. Although optic nerve crush or transection is relatively rare clinically, these approaches are used in animal models and have shed light on important events after optic neuropathy in general. Other animal models of optic neuropathies include glaucoma induced by the elevation of the intraocular pressure through cauterization of the trabecular meshwork or intraocular injection of hypertonic solution [42, 43], AION [28•, 44-46], posterior ischemic optic neuropathy (PION) [47], and optic neuritis $[48,49]$. Photochemical thrombosis animal models of AION produce severe optic nerve head edema and swelling [44-46, 50-53] and abnormal visual evoked potential responses $24 \mathrm{~h}$ after the insult [44-46]. Acutely, there is also prominent microglial activation and post-ischemic inflammatory response, apoptosis of the optic nerve oligodendrocytes within 6 days, and demyelination [44, 50, 53, 54]. By week 1 , there is prominent, progressive optic nerve demyelination that marches toward the distal optic nerve, more apoptosis of optic nerve oligodendrocytes, and massive degeneration of RGC axons (annexin $\mathrm{V}^{+}$) $[44,45,50,55]$. By week 3 , there is relatively stable, irreversible loss of oligodendrocytes, RGCs, and thinning of the ganglion cell complex on optical coherence tomography and in optic nerve histology [29, 44 -46, 50, 51, 55 ,
56], and the severity of the acute retinal swelling seems to correlate with the extent of chronic thinning [57].

In these animal models of optic neuropathies, we know that optic nerve injury leads to early and massive anterograde and retrograde axonal degeneration of the RGC axons, early loss of optic nerve oligodendrocytes, and loss of RGC somata [44-46, 48, 50, 58]. This means that in order to restore vision, regenerative therapy has to facilitate regrowth of almost the entire length of the optic nerve and these axons need to be supported by healthy optic nerve glia. Depending on the type of injury and distance from the cell body, RGC degeneration varies in intensity and speed. For instance, if axonal injury occurs close to RGC cell body, the degeneration is faster and more devastating, likely as a consequence of the time of transport of retrograde signals, as well as of the loss of the trophic support from the distal nerve [31]. Therefore, animal models of optic nerve injury can differently affect RGC survival. For instance, in rats, intraorbital optic nerve transection results in fast loss of RGCs, starting at 4 days post injury, and reducing the RGC number to less than $5 \%$ in 2 weeks [31], while intraorbital optic nerve crush reduces RGC population to $10-25 \%$ in 2 weeks and to $2-15 \%$ in 4 weeks, and the variability is probably due to different methods used to count RGCs [59, 60]. Similarly, in mice, intraorbital optic nerve crush reduces RGC population to $\sim 50 \%$ after 1 week, to $~$ $25 \%$ in 2 weeks, and to less than $10 \%$ in 8 weeks [61].

\section{Protection of Retina vs. Optic Nerve: Lessons from Neuroprotection}

Treatment of optic neuropathies like glaucoma has primarily focused on neuroprotection, i.e., rescuing RGC somata. However, increased neuronal survival is not consistently linked with proportionately greater axon regeneration, which has been shown in several studies using neurotrophic factor deliveries [62]. Following axonal damage, blockade of axonal transport of proteins may impair the arrival of neurotrophic factors and other essential molecules for RGC survival. The consequent neurotrophic factor deprivation is one of the current hypotheses to explain CNS neuronal death following axonal damage. During development, these factors are produced in a limited amount by neuronal targets, and only neurons that are exposed to sufficient levels of these molecules survive, a process that is essential for correct innervation [1]. Adult retinal neurons receive trophic support from glial cells as well as from their targets, and loss of connections may affect neuronal fate. Indeed, several studies using exogenous neurotrophins improved RGC survival, although not always this resulted in increased axonal regeneration [63-67].

For instance, exogenous BDNF, whether delivered intravitreally as recombinant protein or by gene transfer, delays RGC death but does not salvage axons [64]. BDNF binds to tyrosine kinase $\mathrm{B}$ (TrkB) receptor to trigger intracellular 
pathways related to cell survival, including phosphorylation of cyclic adenosine monophosphate (cAMP) response element-binding protein and transcription of survival genes $B c l-2$ and $B c l-x[14,68]$.

Exogenous delivery of nerve growth factor (NGF) protected RGCs in models of axotomy, ischemia, and ocular hypertension [69-71], whereas other studies did not observe therapeutic effects $[72,73]$. Complex effects of NGF are attributed to the variable activation of its receptors, which can lead to cell survival or death. NGF receptors are tyrosine kinase A (TrkA), which is specific to NGF, and p75NTR, which binds to all neurotrophins and precursors [74, 75]. Increased levels of NGF precursor proNGF associated with a low TrkA/p75NTR ratio are currently associated to cell death signaling through p75NTR activation [14, 76, 77].

Topical administration of highly purified murine NGF improved visual field in three advanced glaucoma patients [65], and recombinant human NGF (rhNGF) can be delivered as eye drops to exert biological function in the posterior segment of the eye. Indeed, in a rat model of optic nerve crush, rhNGF eye drops reduced the co-expression of NOGO-A and p75NTR at glial scar-forming cells at crush site borders, and improved TrkA/p75NTR and proNGF/NGF ratios, thus resulting in activation of survival and regeneration program during the first 2 weeks after injury [66]. Importantly, rhNGF eye drops were well tolerated in clinical trials $[78,79]$ and therefore can be a potential treatment of optic neuropathies. Nevertheless, although rhNGF counteracted the enhancement of p75NTR, NOGO-R, and ROCK 2 in the retina 7 days after injury, it had a modest effect on axon regrowth by 14 days after crush. Future studies may better determine the optimal dosage and duration of treatment, and likely combine it with additional axon regenerative approaches.

\section{Endogenous vs. Exogenous Approaches in Regenerative Therapy}

Strategies to improve axonal growth include attempts to shift the CNS inhibitory environment to a permissive one $[10,80]$, and to stimulate intrinsic regenerative programs of RGCs. One of the first approaches to stimulate robust axon regeneration was to increase ocular inflammation after lens injury or intraocular injection of zymosan, a yeast cell wall preparation [81-83]. The regenerative effects were associated to the recruitment of neutrophils and macrophages that release oncomodulin and require cAMP elevation [81, 84], while a divergent line attributed it to the activation of signal transducer and activator of transcription 3 in RGCs and to glial-derived ciliary neurotrophic factor and leukemia inhibitory factor [85]. In the past decade, gene deletion approaches, cell therapies, visual stimulation, and combined approaches were described to be more efficient in achieving robust axonal regeneration.

\section{Genetic Approaches}

The intrinsic ability of RGCs to regenerate has been stimulated by genetic approaches to manipulate cell growth-related molecules such as the mammalian target of rapamycin (mTOR), Kruppel-like family transcription factors, and the suppressor of cytokine signaling 3 (Socs3) [86-89]. Phosphatase and tensin homolog (Pten) deletion as a way to activate phosphatidylinositol-3-kinase-AKT-mTOR pathway has been intensively explored in the past 10 years and AKT was identified as the nodal point that regulates adult CNS axon regeneration. However, a yet unidentified AKTindependent pathway is required for stimulating more robust axonal growth [62]. Co-deletion of Pten and Socs3 has stimulated RGC axons to grow up to the suprachiasmatic nucleus and reintegrate with the local circuitry after optic nerve crush [86, 90]. After overexpression of $C$-myc plus co-deletion of Pten and Socs3, several axons crossed the optic chiasm 4 weeks after crush, but the number of regenerated axons was reduced after 8 weeks, possibly due to the elimination of axons that have not formed synaptic connections [91]. Limited reconnection and functional recovery following gene deletion experiments could be also due to the differential response of RGC subtypes. Indeed, alpha-RGCs accounted for nearly all regeneration following deletion of Pten [92], suggesting that the modulation of multiple pathways is required to induce a higher number of RGCs to regenerate.

\section{Combinatorial Approaches}

The combination of Pten deletion with zymosan injection and elevation of cAMP resulted in approximately 10 -fold more regeneration than Pten deletion or zymosan injection alone $[93 \cdot$, 94]. After 10-12 weeks, regenerating fibers reached the contralateral dorsal lateral geniculate nucleus, in association to synaptic markers, and mice had improved depth perception, circadian activity, and optokinetic reflex [93•].

In addition to gene deletion, biased visual stimulation is a powerful approach. Goldberg and coworkers showed that RGC axonal growth in response to trophic factors is dramatically increased by electrical activity [95]. Based on these evidences, Lim and coworkers used visual stimulation to increase RGC electrical activity and induce regeneration after optic nerve crush [96-]. In addition, based on activity-dependent behavioral recovery after forced use of the impaired limb after corticospinal tract injury [97], they sutured the fellow eye, creating a biased visual stimulation. After combining that with mTOR activation, regenerated axons reached the optic chiasm, suprachiasmatic, ventral and dorsal lateral geniculate nuclei, pretectum, and accessory optic targets in the brainstem and superior colliculus. Animals had improved optokinetic reflex and recovered 
the perception of an over-head looming stimulus, which depends on the retino-collicular pathway. Pupillary light reflex and depth perception were not recovered, although reinnervation had been observed in the appropriate targets [96•].

These experiments revealed a remarkable ability of adult mammals RGCs to reenter the growth phase and find their targets as during development. However, the incomplete visual behavior recovery may be partially explained by incorrect synapse formation and insufficient number of regenerating axons. Another issue may be the lack of myelination of regenerated axons. Indeed, voltage-gated potassium channel blocker 4-aminopyridine improved the conduction of RGC axons and the performance of animals on the optokinetic reflex test after optic tract transection [98].

\section{Cell Therapy Approaches}

Different research groups have used embryonic stem cells or induced pluripotent stem cells to generate RGCs that could replace the lost cells [99-101]. Although these newly generated cells express RGC markers, after injection of stem cell-derived or postnatal purified RGCs into the vitreous chamber, integration into the retina is still not always achieved, although some promising results have been described [99, 102]. The combination of cell transplantation with axon regenerative and guidance approaches is likely the route for highly ambitious studies aiming to replace lost RGCs in end-stage optic neuropathies.

Meanwhile, cell therapies performed to exert neuroprotection and support regeneration of RGCs have also emerged [43, $59,60,103]$, taking advantage of a possibly shorter road to the clinic than cell replacement therapies [104] but so far showing less robust results than gene manipulation approaches. Importantly, the transplantation of cells into the eye without supporting preclinical data and appropriate procedures can lead to severe visual loss [105].

Bone marrow mononuclear cells, bone marrow-derived mesenchymal stem cells (MSCs), and MSCs from other tissues such as the adipose tissue and dental pulp have been tested in animal models of optic neuropathies [103, 104, 106]. Most studies showed neuroprotective and axon regenerative effects of such cells [42, 43, 59, 107, 108], but their mechanisms of action are still being investigated. The current view is that MSCs exhibit neurotrophic effects and modulate inflammation [109-112] through secretion of factors that target retinal cells as soluble factors $[108,113]$ or inside extracellularly secreted vesicles containing a variety of molecules-ranging from small regulatory microRNAs, which are short noncoding RNA molecules, to trophic factors $[114,115]$. Because intravitreally injected MSCs can persist in the eye [59], a potential detrimental effect on light transmission should be investigated. A delivery system that introduces the secretome of the MSCs without injecting the cells into the vitreous can avoid these issues.

\section{Intravitreal vs. Optic Nerve Targeting of Exogenous Therapies}

The vast majority of the ocular approaches to treat optic neuropathies use intravitreally targeted drugs, viral vectors, or cells, which is in close proximity of the RGC somata but not the optic nerve - the initial site of injury. This means these therapies are not effectively treating the axons or the optic nerve glia, which are crucial in shaping neuronal fate [35॰]. Recent data have shown that pharmacological enhancement of myelination and axonal conduction [98] and transplantation of oligodendrocyte progenitors [116] are promising therapeutic approaches in the treatment of CNS injuries, including optic neuropathies.

Direct targeting of the optic nerve will be an important approach in future treatment of optic neuropathies because this approach delivers drug to the initial site of injury, has less CNS and systemic side effects, and potentially be combined with neuroprotective treatment that target the soma. Because experimental delivery of drugs or cells to the optic nerve is difficult in small animals, our grouped has collaborated with experts in neurosurgery and glial cell biology to develop alternative methods to target different portions of the mouse optic nerve using injections intraorbitally, through the optic foramen, and transcranially [117]. By directly targeting the optic nerve (Fig. 1) with drugs, cells, or biomaterials containing biologically active molecules or even adhered cells, RGC longdistance regeneration, axonal guidance, and myelination may be more efficiently approached than with current strategies.

\section{Considerations of Regenerative Therapies in Acute vs. Chronic Optic Neuropathies}

Treatment will likely be different when comparing acute (e.g., AION) and chronic (e.g., glaucoma) optic neuropathies. This is in part because in acute disease the axons are still not completely lost, so the therapeutic intervention will likely involve control of inflammation, neuroprotective, axon-protective, and glia-protective therapies, or glial cell replacement. On the other hand, in chronic conditions such as glaucoma with advanced vision loss, it is assumed that several RGC axons are already damaged, with loss of RGC somata. In that case, it is necessary to develop therapies to stimulate the regeneration of those axons from surviving RGCs and, at the latest stage disease, cell therapies to replace lost RGCs. This is amongst the most ambitious goals because it requires the integration of new cells, axon growth, and path finding. However, by combining cell replacement with genetic or pharmacological treatments promoting axon growth, new approaches may achieve successful results.

In addition, both acute and chronic optic neuropathies involve axonal injury and cessation of visual transduction in the 
Fig. 1 Methods to approach the rodent optic nerve for regenerative medicine. Strategies to increase optic nerve regeneration mostly target the optic nerve by intravitreal injections. For direct targeting, the optic nerve can be approached in its intraorbital (light blue) or intracranial (dark blue) portions by different methods. The currently described approaches are shown by the red arrows. Dashed lines indicate where the needle is inserted through the tissues

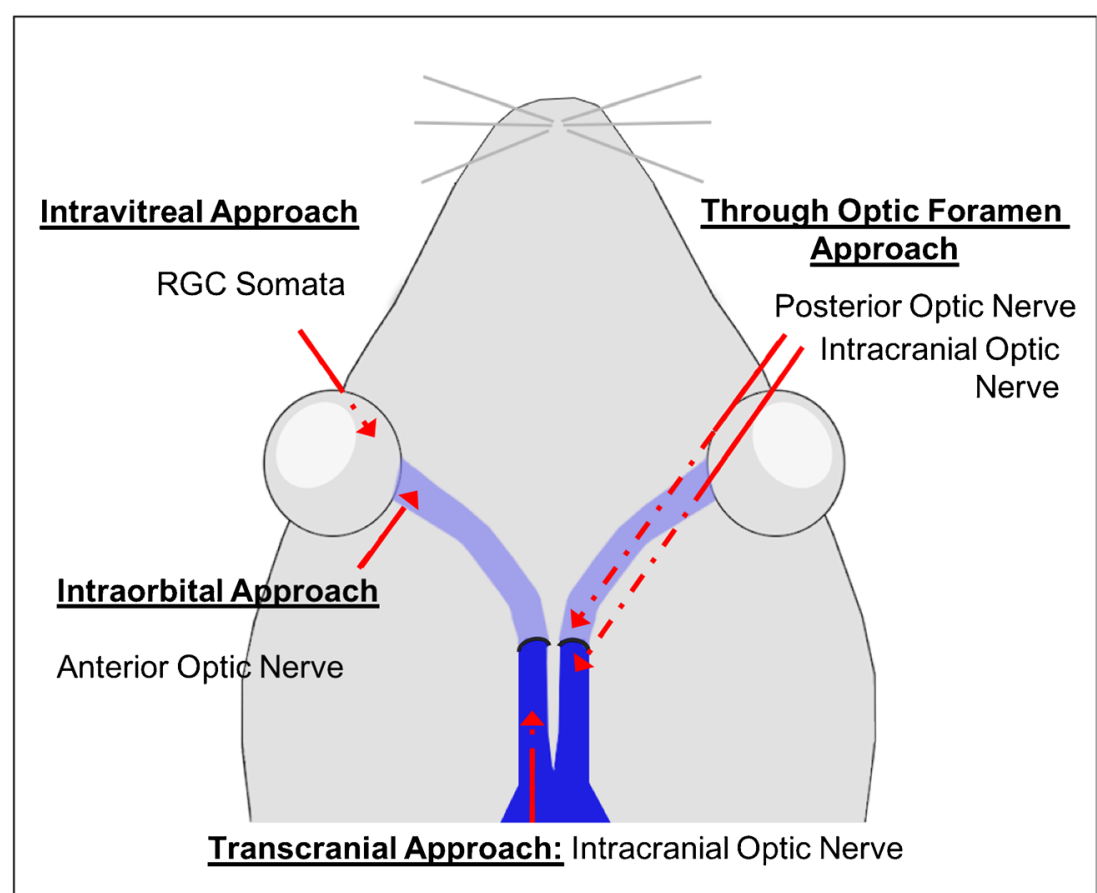

early phase and irreversible, progressive RGC and vision loss in the second phase. In acute optic neuropathies, the first phase is greater in magnitude, while in chronic disease, the second phase seems to be often more devastating. Therefore, the timing of treatment should consider the type and stage of the disease.

Finally, if axon regeneration is a requirement to achieve visual recovery, it is necessary to overcome the inhibitory milieu of the CNS, by modulation of axon growth-inhibitory signaling and cells that configure a toxic environment for neurons to growth. The understanding of how myelin is cleared in the PNS and how CNS glia behaves in different conditions that trigger neuronal degeneration can elucidate new therapeutic targets to prevent irreversible vision loss.

\section{Conclusions}

Optic neuropathies are complex diseases involving damage to RGC somata and axons that form the optic nerve, as well as surrounding glia. While there is currently no clinically available therapy to efficiently sustain RGC survival and promote axonal regrowth after injury, preclinical studies in small rodents are changing the way such diseases are seen as irreversible causes of vision loss. Robust axonal regeneration and target reconnection have been achieved with combinatorial approaches, involving gene deletion, pharmacological approaches, and visual stimulation. On the other hand, cell therapies with paracrine activity and more ambitious cell replacement strategies are also being investigated. Future approaches should address treatment of the axonopathy in acute and chronic optic neuropathies, including axon-protective and glia-protective approaches, likely in combination with existing approaches targeting RGC cell bodies and intrinsic mechanisms of axon regeneration.

\section{Compliance with Ethical Standards}

Conflict of Interest Louise A. Mesentier-Louro and Yaping Joyce Liao declare that they have no conflict of interest.

Human and Animal Rights and Informed Consent This article does not contain any studies with human or animal subjects performed by any of the authors.

OpenAccessThis article is distributed under the terms of the Creative Commons Attribution 4.0 International License (http://creativecommons.org/ licenses/by/4.0/), which permits unrestricted use, distribution, and reproduction in any medium, provided you give appropriate credit to the original author(s) and the source, provide a link to the Creative Commons license, and indicate if changes were made.

Publisher's Note Springer Nature remains neutral with regard to jurisdictional claims in published maps and institutional affiliations.

\section{References}

Papers of particular interest, published recently, have been highlighted as:

- Of importance

1. Vrabec JP, Levin LA. The neurobiology of cell death in glaucoma. Eye. 2007;21(Suppl 1):S11-4. https://doi.org/10.1038/sj.eye. 6702880 . 
2. Benowitz LI, He Z, Goldberg JL. Reaching the brain: advances in optic nerve regeneration. Exp Neurol. 2017;287:365-73. https:// doi.org/10.1016/j.expneurol.2015.12.015.

3. Bessero AC, Clarke PG. Neuroprotection for optic nerve disorders. Curr Opin Neurol. 2010;23:10-5. https://doi.org/10.1097/ WCO.0b013e3283344461.

4. Hayreh SS. Ischemic optic neuropathy. Prog Retin Eye Res. 2009;28:34-62. https://doi.org/10.1016/j.preteyeres.2008.11.002.

5. Sun MH, Liao YJ. Structure-function analysis of nonarteritic anterior ischemic optic neuropathy and age-related differences in outcome. J Neuroophthalmol. 2017;37:258-64. https://doi.org/ 10.1097/WNO.0000000000000521.

6. Tanaka EM, Ferretti P. Considering the evolution of regeneration in the central nervous system. Nat Rev Neurosci. 2009;10:713-23. https://doi.org/10.1038/nrn2707.

7. Vargas ME, Barres BA. Why is Wallerian degeneration in the CNS so slow? Annu Rev Neurosci. 2007;30:153-79. https://doi. org/10.1146/annurev.neuro.30.051606.094354.

8. Sauve Y, Gaillard F. Regeneration in the visual system of adult mammals. In: Kolb H, Fernandez E, Nelson R, eds. Webvision: The Organization of the Retina and Visual System. Salt Lake City (UT). 1995

9. Ramón y Cajal S, May RM. Degeneration and regeneration of the central nervous system. London: Oxford University Press, Humphrey Milford; 1928.

10. Villegas-Perez MP, Vidal-Sanz M, Bray GM, Aguayo AJ. Influences of peripheral nerve grafts on the survival and regrowth of axotomized retinal ganglion cells in adult rats. J Neurosci. $1988 ; 8: 265-80$.

11. Soto I, Howell GR. The complex role of neuroinflammation in glaucoma. Cold Spring Harb Perspect Med. 2014;4. https://doi. org/10.1101/cshperspect.a017269.

12. Tham YC, Li X, Wong TY, Quigley HA, Aung T, Cheng CY. Global prevalence of glaucoma and projections of glaucoma burden through 2040: a systematic review and meta-analysis. Ophthalmology. 2014;121:2081-90. https://doi.org/10.1016/j. ophtha.2014.05.013.

13. Weinreb RN, Aung T, Medeiros FA. The pathophysiology and treatment of glaucoma: a review. JAMA. 2014;311:1901-11. https://doi.org/10.1001/jama.2014.3192.

14. Almasieh M, Wilson AM, Morquette B, Cueva Vargas JL, Di Polo A. The molecular basis of retinal ganglion cell death in glaucoma. Prog Retin Eye Res. 2012;31:152-81. https://doi.org/10.1016/j. preteyeres.2011.11.002.

15. Pereira WL, Reiche EM, Kallaur AP, Kaimen-Maciel DR. Epidemiological, clinical, and immunological characteristics of neuromyelitis optica: a review. J Neurol Sci. 2015;355:7-17. https://doi.org/10.1016/j.jns.2015.05.034.

16. Arnold AC. Pathogenesis of nonarteritic anterior ischemic optic neuropathy. J Neuroophthalmol. 2003;23:157-63.

17. Hayreh SS. Anterior ischaemic optic neuropathy. I Terminology and pathogenesis. Br J Ophthalmol. 1974;58:955-63.

18. Biousse V, Newman NJ. Ischemic optic neuropathies. N Engl J Med. 2015;372:2428-36. https://doi.org/10.1056/ NEJMra1413352.

19. Behbehani R. Clinical approach to optic neuropathies. Clin Ophthalmol. 2007;1:233-46.

20. Ghaffarieh A, Levin LA. Optic nerve disease and axon pathophysiology. Int Rev Neurobiol. 2012;105:1-17. https://doi.org/10. 1016/B978-0-12-398309-1.00002-0.

21. Carelli V, La Morgia C, Valentino ML, Barboni P, Ross-Cisneros FN, Sadun AA. Retinal ganglion cell neurodegeneration in mitochondrial inherited disorders. Biochim Biophys Acta. 1787;2009: 518-28. https://doi.org/10.1016/j.bbabio.2009.02.024.
22. La Morgia C, Carbonelli M, Barboni P, Sadun AA, Carelli V. Medical management of hereditary optic neuropathies. Front Neurol. 2014;5:141. https://doi.org/10.3389/fneur.2014.00141.

23. Danesh-Meyer HV, Birch H, Ku JY, Carroll S, Gamble G. Reduction of optic nerve fibers in patients with Alzheimer disease identified by laser imaging. Neurology. 2006;67:1852-4. https:// doi.org/10.1212/01.wnl.0000244490.07925.8b.

24. London A, Benhar I, Schwartz M. The retina as a window to the brain-from eye research to CNS disorders. Nat Rev Neurol. 2013;9:44-53. https://doi.org/10.1038/nrneurol.2012.227.

25. Tamm ER, Ethier CR, Lasker IIoA, Glaucomatous Neurodegeneration P. Biological aspects of axonal damage in glaucoma: a brief review. Exp Eye Res. 2017;157:5-12. https:// doi.org/10.1016/j.exer.2017.02.006.

26. Quigley HA, McKinnon SJ, Zack DJ, Pease ME, KerriganBaumrind LA, Kerrigan DF, et al. Retrograde axonal transport of BDNF in retinal ganglion cells is blocked by acute IOP elevation in rats. Invest Ophthalmol Vis Sci. 2000;41:3460-6.

27. Shah SH, Goldberg JL. The role of axon transport in neuroprotection and regeneration. Dev Neurobiol. 2018;78:998-1010. https:// doi.org/10.1002/dneu.22630.

28. Lee GH, Stanford MP, Shariati MA, Ma JH, Liao YJ. Severe, early axonal degeneration following experimental anterior ischemic optic neuropathy. Invest Ophthalmol Vis Sci. 2014;55:7111-8. https://doi.org/10.1167/iovs.14-14603. This study used novel in vivo methods to describe early axonal degeneration after anterior ischemic optic neuropathy in a rodent animal model.

29. Slater BJ, Mehrabian Z, Guo Y, Hunter A, Bernstein SL. Rodent anterior ischemic optic neuropathy (rAION) induces regional retinal ganglion cell apoptosis with a unique temporal pattern. Invest Ophthalmol Vis Sci. 2008;49:3671-6. https://doi.org/10.1167/ iovs.07-0504.

30. Johnson EM Jr, Deckwerth TL. Molecular mechanisms of developmental neuronal death. Annu Rev Neurosci. 1993;16:31-46. https://doi.org/10.1146/annurev.ne.16.030193.000335.

31. Berkelaar M, Clarke DB, Wang YC, Bray GM, Aguayo AJ. Axotomy results in delayed death and apoptosis of retinal ganglion cells in adult rats. J Neurosci. 1994;14:4368-74.

32. Li HY, Ruan YW, Ren CR, Cui Q, So KF. Mechanisms of secondary degeneration after partial optic nerve transection. Neural Regen Res. 2014;9:565-74. https://doi.org/10.4103/1673-5374. 130093.

33. Malone P, Miao H, Parker A, Juarez S, Hernandez MR. Pressure induces loss of gap junction communication and redistribution of connexin 43 in astrocytes. Glia. 2007;55:1085-98. https://doi.org/ 10.1002/glia.20527.

34. Silver J, Schwab ME, Popovich PG. Central nervous system regenerative failure: role of oligodendrocytes, astrocytes, and microglia. Cold Spring Harb Perspect Biol. 2015;7:a020602. https://doi.org/10.1101/cshperspect.a020602.

35. Liddelow SA, Guttenplan KA, Clarke LE, Bennett FC, Bohlen CJ, Schirmer L, et al. Neurotoxic reactive astrocytes are induced by activated microglia. Nature. 2017;541:481-7. https://doi.org/ 10.1038 /nature21029. This study describes novel roles for glial cells differential activation after CNS injury.

36. Nave KA. Myelination and support of axonal integrity by glia. Nature. 2010;468:244-52. https://doi.org/10.1038/nature09614.

37. Baltan S. Can lactate serve as an energy substrate for axons in good times and in bad, in sickness and in health? Metab Brain Dis. 2015;30:25-30. https://doi.org/10.1007/s11011-014-9595-3.

38. Hirrlinger J, Nave KA. Adapting brain metabolism to myelination and long-range signal transduction. Glia. 2014;62:1749-61. https://doi.org/10.1002/glia.22737.

39. Lee Y, Morrison BM, Li Y, Lengacher S, Farah MH, Hoffman PN, et al. Oligodendroglia metabolically support axons and contribute 
to neurodegeneration. Nature. 2012;487:443-8. https://doi.org/10. 1038/nature11314.

40. Almad A, Sahinkaya FR, McTigue DM. Oligodendrocyte fate after spinal cord injury. Neurotherapeutics. 2011;8:262-73. https://doi.org/10.1007/s13311-011-0033-5.

41. Brosius Lutz A, Chung WS, Sloan SA, Carson GA, Zhou L, Lovelett E, et al. Schwann cells use TAM receptor-mediated phagocytosis in addition to autophagy to clear myelin in a mouse model of nerve injury. Proc Natl Acad Sci. 2017;114:E8072-80. https://doi.org/10.1073/pnas.1710566114.

42. Li N, Li XR, Yuan JQ. Effects of bone-marrow mesenchymal stem cells transplanted into vitreous cavity of rat injured by ischemia/ reperfusion. Graefes Arch Clin Exp Ophthalmol. 2009;247:50314. https://doi.org/10.1007/s00417-008-1009-y.

43. Johnson TV, Bull ND, Hunt DP, Marina N, Tomarev SI, Martin KR. Neuroprotective effects of intravitreal mesenchymal stem cell transplantation in experimental glaucoma. Invest Ophthalmol Vis Sci. 2010;51:2051-9. https://doi.org/10.1167/iovs.09-4509.

44. Bernstein SL, Guo Y, Kelman SE, Flower RW, Johnson MA. Functional and cellular responses in a novel rodent model of anterior ischemic optic neuropathy. Invest Ophthalmol Vis Sci. 2003;44:4153-62.

45. Bernstein SL, Johnson MA, Miller NR. Nonarteritic anterior ischemic optic neuropathy (NAION) and its experimental models. Prog Retin Eye Res. 2011;30:167-87. https://doi.org/10.1016/j. preteyeres.2011.02.003.

46. Pangratz-Fuehrer S, Kaur K, Ousman SS, Steinman L, Liao YJ. Functional rescue of experimental ischemic optic neuropathy with alphaB-crystallin. Eye. 2011;25:809-17. https://doi.org/10.1038/ eye.2011.42.

47. Wang Y, Brown DP Jr, Duan Y, Kong W, Watson BD, Goldberg JL. A novel rodent model of posterior ischemic optic neuropathy. JAMA Ophthalmol. 2013;131:194-204. https://doi.org/10.1001/ 2013.jamaophthalmol.271.

48. Levkovitch-Verbin H. Animal models of optic nerve diseases. Eye. 2004;18:1066-74. https://doi.org/10.1038/sj.eye.6701576.

49. Matsunaga Y, Kezuka T, An X, Fujita K, Matsuyama N, Matsuda $\mathrm{R}$, et al. Visual functional and histopathological correlation in experimental autoimmune optic neuritis. Invest Ophthalmol Vis Sci. 2012;53:6964-71. https://doi.org/10.1167/iovs.12-10559.

50. Goldenberg-Cohen N, Guo Y, Margolis F, Cohen Y, Miller NR, Bernstein SL. Oligodendrocyte dysfunction after induction of experimental anterior optic nerve ischemia. Invest Ophthalmol Vis Sci. 2005;46:2716-25. https://doi.org/10.1167/iovs.04-0547.

51. Ho JK, Stanford M, Shariati MA, Dalal R, Liao YJ. Optical coherence tomography study of experimental anterior ischemic optic neuropathy and histologic confirmation. Invest Ophthalmol Vis Sci. 2013;54:5981-8. https://doi.org/10.1167/iovs.13-12419.

52. Yu C, Ho JK, Liao YJ. Subretinal fluid is common in experimental non-arteritic anterior ischemic optic neuropathy. Eye. 2014;28: 1494-501. https://doi.org/10.1038/eye.2014.220.

53. Slater BJ, Vilson FL, Guo Y, Weinreich D, Hwang S, Bernstein SL. Optic nerve inflammation and demyelination in a rodent model of nonarteritic anterior ischemic optic neuropathy. Invest Ophthalmol Vis Sci. 2013;54:7952-61. https://doi.org/10.1167/ iovs.13-12064.

54. Salgado C, Vilson F, Miller NR, Bernstein SL. Cellular inflammation in nonarteritic anterior ischemic optic neuropathy and its primate model. Arch Ophthalmol. 2011;129:1583-91. https://doi. org/10.1001/archophthalmol.2011.351.

55. Dratviman-Storobinsky O, Hasanreisoglu M, Offen D, Barhum Y, Weinberger D, Goldenberg-Cohen N. Progressive damage along the optic nerve following induction of crush injury or rodent anterior ischemic optic neuropathy in transgenic mice. Mol Vis. 2008; $14: 2171-9$.
56. Zhang C, Guo Y, Slater BJ, Miller NR, Bernstein SL. Axonal degeneration, regeneration and ganglion cell death in a rodent model of anterior ischemic optic neuropathy (rAION). Exp Eye Res. 2010;91:286-92. https://doi.org/10.1016/j.exer.2010.05.021.

57. Johnson MA, Miller NR, Nolan T, Bernstein SL. Peripapillary retinal nerve fiber layer swelling predicts peripapillary atrophy in a primate model of nonarteritic anterior ischemic optic neuropathy. Invest Ophthalmol Vis Sci. 2016;57:527-32. https://doi.org/10. 1167/iovs.15-17880.

58. Shariati MA, Park JH, Liao YJ. Optical coherence tomography study of retinal changes in normal aging and after ischemia. Invest Ophthalmol Vis Sci. 2015;56:2790-7. https://doi.org/10. 1167/iovs.14-15145.

59. Mesentier-Louro LA, Zaverucha-do-Valle C, da Silva-Junior AJ, Nascimento-Dos-Santos G, Gubert F, de Figueiredo AB, et al. Distribution of mesenchymal stem cells and effects on neuronal survival and axon regeneration after optic nerve crush and cell therapy. PLoS One. 2014;9:e110722. https://doi.org/10.1371/ journal.pone.0110722.

60. Zaverucha-do-Valle C, Gubert F, Bargas-Rega M, Coronel JL, Mesentier-Louro LA, Mencalha A, et al. Bone marrow mononuclear cells increase retinal ganglion cell survival and axon regeneration in the adult rat. Cell Transplant. 2011;20:391-406. https:// doi.org/10.3727/096368910X524764.

61. Levkovitch-Verbin H, Harris-Cerruti C, Groner Y, Wheeler LA, Schwartz M, Yoles E. RGC death in mice after optic nerve crush injury: oxidative stress and neuroprotection. Invest Ophthalmol Vis Sci. 2000;41:4169-74.

62. Zhang J, Yang D, Huang H, Sun Y, Hu Y. Coordination of necessary and permissive signals by PTEN inhibition for CNS axon regeneration. Front Neurosci. 2018;12:558. https://doi.org/10. 3389/fnins.2018.00558.

63. Cheng L, Sapieha P, Kittlerova P, Hauswirth WW, Di Polo A. TrkB gene transfer protects retinal ganglion cells from axotomyinduced death in vivo. J Neurosci. 2002;22:3977-86.

64. Pernet V, Di Polo A. Synergistic action of brain-derived neurotrophic factor and lens injury promotes retinal ganglion cell survival, but leads to optic nerve dystrophy in vivo. Brain. 2006;129: 1014-26. https://doi.org/10.1093/brain/awl015.

65. Lambiase A, Aloe L, Centofanti M, Parisi V, Bao SN, Mantelli F, et al. Experimental and clinical evidence of neuroprotection by nerve growth factor eye drops: implications for glaucoma. Proc Natl Acad Sci. 2009;106:13469-74. https://doi.org/10.1073/pnas. 0906678106.

66. Mesentier-Louro LA, Rosso P, Carito V, Mendez-Otero R, Santiago MF, Rama P, et al. Nerve growth factor role on retinal ganglion cell survival and axon regrowth: effects of ocular administration in experimental model of optic nerve injury. Mol Neurobiol. 2018. https://doi.org/10.1007/s12035-018-1154-1.

67. Park K, Luo JM, Hisheh S, Harvey AR, Cui Q. Cellular mechanisms associated with spontaneous and ciliary neurotrophic factorcAMP-induced survival and axonal regeneration of adult retinal ganglion cells. J Neurosci. 2004;24:10806-15. https://doi.org/10. 1523/JNEUROSCI.3532-04.2004.

68. Dahlmann-Noor AH, Vijay S, Limb GA, Khaw PT. Strategies for optic nerve rescue and regeneration in glaucoma and other optic neuropathies. Drug Discov Today. 2010;15:287-99. https://doi. org/10.1016/j.drudis.2010.02.007.

69. Carmignoto G, Maffei L, Candeo P, Canella R, Comelli C. Effect of NGF on the survival of rat retinal ganglion cells following optic nerve section. J Neurosci. 1989;9:1263-72.

70. Siliprandi R, Canella R, Carmignoto G. Nerve growth factor promotes functional recovery of retinal ganglion cells after ischemia. Invest Ophthalmol Vis Sci. 1993;34:3232-45.

71. Colafrancesco V, Coassin M, Rossi S, Aloe L. Effect of eye NGF administration on two animal models of retinal ganglion cells 
degeneration. Ann Ist Super Sanita. 2011;47:284-9. https://doi. org/10.4415/ANN_11_03_08.

72. Bai Y, Dergham P, Nedev H, Xu J, Galan A, Rivera JC, et al. Chronic and acute models of retinal neurodegeneration TrkA activity are neuroprotective whereas p75NTR activity is neurotoxic through a paracrine mechanism. J Biol Chem. 2010;285:39392400. https://doi.org/10.1074/jbc.M110.147801.

73. Lebrun-Julien F, Morquette B, Douillette A, Saragovi HU, Di Polo A. Inhibition of p75(NTR) in glia potentiates TrkA-mediated survival of injured retinal ganglion cells. Mol Cell Neurosci. 2009;40: 410-20. https://doi.org/10.1016/j.mcn.2008.12.005.

74. Lewin GR, Carter BD. Neurotrophic factors. Preface. Handb Exp Pharmacol. 2014;220:v-vi.

75. Lee R, Kermani P, Teng KK, Hempstead BL. Regulation of cell survival by secreted proneurotrophins. Science. 2001;294:19458. https://doi.org/10.1126/science.1065057.

76. Cuello AC, Bruno MA, Allard S, Leon W, Iulita MF. Cholinergic involvement in Alzheimer's disease. A link with NGF maturation and degradation. J Mol Neurosci. 2010;40:230-5. https://doi.org/ 10.1007/s12031-009-9238-z.

77. Masoudi R, Ioannou MS, Coughlin MD, Pagadala P, Neet KE, Clewes $\mathrm{O}$, et al. Biological activity of nerve growth factor precursor is dependent upon relative levels of its receptors. J Biol Chem. 2009;284:18424-33. https://doi.org/10.1074/jbc.M109.007104.

78. Falsini B, Iarossi G, Chiaretti A, Ruggiero A, Manni L, GalliResta L, et al. Erratum to: NGF eye-drops topical administration in patients with retinitis pigmentosa, a pilot study. J Transl Med. 2016;14:43. https://doi.org/10.1186/s12967-016-0800-5.

79. Ferrari MP, Mantelli F, Sacchetti M, Antonangeli MI, Cattani F, D'Anniballe G, et al. Safety and pharmacokinetics of escalating doses of human recombinant nerve growth factor eye drops in a double-masked, randomized clinical trial. BioDrugs. 2014;28: 275-83. https://doi.org/10.1007/s40259-013-0079-5.

80. Cen LP, Luo JM, Geng Y, Zhang M, Pang CP, Cui Q. Long-term survival and axonal regeneration of retinal ganglion cells after optic nerve transection and a peripheral nerve graft. Neuroreport. 2012;23:692-7. https://doi.org/10.1097/WNR. 0b013e328355fld6.

81. Kurimoto T, Yin Y, Habboub G, Gilbert HY, Li Y, Nakao S, et al. Neutrophils express oncomodulin and promote optic nerve regeneration. J Neurosci. 2013;33:14816-24. https://doi.org/10.1523/ jneurosci.5511-12.2013

82. Leon S, Yin Y, Nguyen J, Irwin N, Benowitz LI. Lens injury stimulates axon regeneration in the mature rat optic nerve. $\mathrm{J}$ Neurosci. 2000;20:4615-26.

83. Fischer D, Heiduschka P, Thanos S. Lens-injury-stimulated axonal regeneration throughout the optic pathway of adult rats. Exp Neurol. 2001;172:257-72. https://doi.org/10.1006/exnr.2001. 7822.

84. Yin Y, Henzl MT, Lorber B, Nakazawa T, Thomas TT, Jiang F, et al. Oncomodulin is a macrophage-derived signal for axon regeneration in retinal ganglion cells. Nat Neurosci. 2006;9:843-52. https://doi.org/10.1038/nn1701.

85. Leibinger M, Andreadaki A, Diekmann H, Fischer D. Neuronal STAT3 activation is essential for CNTF- and inflammatory stimulation-induced CNS axon regeneration. Cell Death Dis. 2013;4:e805. https://doi.org/10.1038/cddis.2013.310.

86. Sun F, Park KK, Belin S, Wang D, Lu T, Chen G, et al. Sustained axon regeneration induced by co-deletion of PTEN and SOCS3. Nature. 2011;480:372-5. https://doi.org/10.1038/nature10594.

87. Park KK, Liu K, Hu Y, Smith PD, Wang C, Cai B, et al. Promoting axon regeneration in the adult CNS by modulation of the PTEN/mTOR pathway. Science. 2008;322:963-6. https://doi. org/10.1126/science.1161566.

88. Barber A, Farmer K, Martin KR, Smith PD. Retinal regeneration mechanisms linked to multiple cancer molecules: a therapeutic conundrum. Prog Retin Eye Res. 2016;56:19-31. https://oi.org/ 10.1016/j.preteyeres.2016.08.003.

89. Moore DL, Blackmore MG, Hu Y, Kaestner KH, Bixby JL, Lemmon VP, et al. KLF family members regulate intrinsic axon regeneration ability. Science. 2009;326:298-301. https://doi.org/ 10.1126/science.1175737.

90. Li S, He Q, Wang H, Tang X, Ho KW, Gao X, et al. Injured adult retinal axons with Pten and Socs 3 co-deletion reform active synapses with suprachiasmatic neurons. Neurobiol Dis. 2014;73C: 366-76. https://doi.org/10.1016/j.nbd.2014.09.019.

91. Belin S, Nawabi H, Wang C, Tang S, Latremoliere A, Warren P, et al. Injury-induced decline of intrinsic regenerative ability revealed by quantitative proteomics. Neuron. 2015;86:1000-14. https://doi.org/10.1016/j.neuron.2015.03.060.

92. Duan X, Qiao M, Bei F, Kim IJ, He Z, Sanes JR. Subtype-specific regeneration of retinal ganglion cells following axotomy: effects of osteopontin and mTOR signaling. Neuron. 2015;85:1244-56. https://doi.org/10.1016/j.neuron.2015.02.017.

93. de Lima S, Koriyama Y, Kurimoto T, Oliveira JT, Yin Y, Li Y, et al. Full-length axon regeneration in the adult mouse optic nerve and partial recovery of simple visual behaviors. Proc Natl Acad Sci. 2012;109:9149-54. https://doi.org/10.1073/pnas. 1119449109. This study was pioneer in achieving full-length axon regeneration and recovery of visual behaviors.

94. Kurimoto T, Yin Y, Omura K, Gilbert HY, Kim D, Cen LP, et al. Long-distance axon regeneration in the mature optic nerve: contributions of oncomodulin, cAMP, and pten gene deletion. J Neurosci. 2010;30:15654-63. https://doi.org/10.1523/ JNEUROSCI.4340-10.2010.

95. Goldberg JL, Espinosa JS, Xu Y, Davidson N, Kovacs GT, Barres BA. Retinal ganglion cells do not extend axons by default: promotion by neurotrophic signaling and electrical activity. Neuron. 2002;33:689-702.

96. Lim JH, Stafford BK, Nguyen PL, Lien BV, Wang C, Zukor K, et al. Neural activity promotes long-distance, target-specific regeneration of adult retinal axons. Nat Neurosci. 2016;19:107384. https://doi.org/10.1038/nn.4340. This study was pioneer in achieving multiple target reinnervation after visual stimulation and combinatorial approaches.

97. Maier IC, Baumann K, Thallmair M, Weinmann O, Scholl J, Schwab ME. Constraint-induced movement therapy in the adult rat after unilateral corticospinal tract injury. J Neurosci. 2008;28:9386-403. https://doi.org/10.1523/JNEUROSCI.169708.2008 .

98. Bei F, Lee HH, Liu X, Gunner G, Jin H, Ma L, et al. Restoration of visual function by enhancing conduction in regenerated axons. Cell. 2016;164:219-32. https://doi.org/10.1016/j.cell.2015.11. 036.

99. Chen M, Chen Q, Sun X, Shen W, Liu B, Zhong X, et al. Generation of retinal ganglion-like cells from reprogrammed mouse fibroblasts. Invest Ophthalmol Vis Sci. 2010;51:5970-8. https://doi.org/10.1167/iovs.09-4504.

100. Jagatha B, Divya MS, Sanalkumar R, Indulekha CL, Vidyanand S, Divya TS, et al. In vitro differentiation of retinal ganglion-like cells from embryonic stem cell derived neural progenitors. Biochem Biophys Res Commun. 2009;380:230-5. https://doi. org/10.1016/j.bbrc.2009.01.038.

101. Parameswaran S, Dravid SM, Teotia P, Krishnamoorthy RR, Qiu $\mathrm{F}$, Toris $\mathrm{C}$, et al. Continuous non-cell autonomous reprogramming to generate retinal ganglion cells for glaucomatous neuropathy. Stem Cells. 2015;33:1743-58. https://doi.org/10.1002/stem.1987.

102. Venugopalan P, Wang Y, Nguyen T, Huang A, Muller KJ, Goldberg JL. Transplanted neurons integrate into adult retinas and respond to light. Nat Commun. 2016;7:10472. https://doi. org/10.1038/ncomms 10472 . 
103. Mead B, Berry M, Logan A, Scott RA, Leadbeater W, Scheven BA. Stem cell treatment of degenerative eye disease. Stem Cell Res. 2015;14:243-57. https://doi.org/10.1016/j.scr.2015.02.003.

104. Mesentier-Louro LA, Zaverucha-do-Valle C, Rosado-de-Castro PH, Silva-Junior AJ, Pimentel-Coelho PM, Mendez-Otero R, et al. Bone marrow-derived cells as a therapeutic approach to optic nerve diseases. Stem Cells Int. 2016;2016:5078619-6. https://doi. org/10.1155/2016/5078619.

105. Kuriyan AE, Albini TA, Townsend JH, Rodriguez M, Pandya HK, Leonard RE 2nd, et al. Vision loss after intravitreal injection of autologous "stem cells" for AMD. N Engl J Med. 2017;376:104753. https://doi.org/10.1056/NEJMoa1609583.

106. Emre E, Yuksel N, Duruksu G, Pirhan D, Subasi C, Erman G, et al. Neuroprotective effects of intravitreally transplanted adipose tissue and bone marrow-derived mesenchymal stem cells in an experimental ocular hypertension model. Cytotherapy. 2015;17: 543-59. https://doi.org/10.1016/j.jcyt.2014.12.005.

107. Tan H, Kang X, Lu S, Liu L. The therapeutic effects of bone marrow mesenchymal stem cells after optic nerve damage in the adult rat. Clin Interv Aging. 2015;10:487-90. https://doi.org/10. 2147/CIA.S75319.

108. Mead B, Logan A, Berry M, Leadbeater W, Scheven BA. Paracrine-mediated neuroprotection and neuritogenesis of axotomised retinal ganglion cells by human dental pulp stem cells: comparison with human bone marrow and adipose-derived mesenchymal stem cells. PLoS One. 2014;9:e109305. https://doi. org/10.1371/journal.pone.0109305.

109. Quertainmont R, Cantinieaux D, Botman O, Sid S, Schoenen J, Franzen R. Mesenchymal stem cell graft improves recovery after spinal cord injury in adult rats through neurotrophic and proangiogenic actions. PLoS One. 2012;7:e39500. https://doi.org/ 10.1371/journal.pone.0039500.

110. Giunti D, Parodi B, Usai C, Vergani L, Casazza S, Bruzzone S, et al. Mesenchymal stem cells shape microglia effector functions through the release of CX3CL1. Stem Cells. 2012;30:2044-53. https://doi.org/10.1002/stem.1174.

111. Lee JK, Schuchman EH, Jin HK, Bae JS. Soluble CCL5 derived from bone marrow-derived mesenchymal stem cells and activated by amyloid beta ameliorates Alzheimer's disease in mice by recruiting bone marrow-induced microglia immune responses. Stem Cells. 2012;30:1544-55. https://doi.org/10.1002/stem.1125.

112. Millan-Rivero JE, Nadal-Nicolas FM, Garcia-Bernal D, SobradoCalvo P, Blanquer M, Moraleda JM, et al. Human Wharton's jelly mesenchymal stem cells protect axotomized rat retinal ganglion cells via secretion of anti-inflammatory and neurotrophic factors. Sci Rep. 2018;8:16299. https://doi.org/10.1038/s41598-01834527-z.

113. Johnson TV, DeKorver NW, Levasseur VA, Osborne A, Tassoni A, Lorber B, et al. Identification of retinal ganglion cell neuroprotection conferred by platelet-derived growth factor through analysis of the mesenchymal stem cell secretome. Brain. 2014;137: 503-19. https://doi.org/10.1093/brain/awt292.

114. Mead B, Tomarev S. Bone marrow-derived mesenchymal stem cells-derived exosomes promote survival of retinal ganglion cells through miRNA-dependent mechanisms. Stem Cells Transl Med. 2017;6:1273-85. https://doi.org/10.1002/sctm.16-0428.

115. Bruno S, Camussi G. Exploring mesenchymal stem cell-derived extracellular vesicles in acute kidney injury. Methods Mol Biol. 2014;1213:139-45. https://doi.org/10.1007/978-1-4939-1453-1_ 12.

116. Li N, Leung GK. Oligodendrocyte precursor cells in spinal cord injury: a review and update. Biomed Res Int. 2015;2015:23519520. https://doi.org/10.1155/2015/235195.

117. Mesentier-Louro LA, Dodd R, Domizi P, Nobuta H, Wernig M, Wernig G, et al. Direct targeting of the mouse optic nerve for therapeutic delivery. J Neurosci Methods. 2018;313:1-5. https:// doi.org/10.1016/j.jneumeth.2018.10.038. 